\title{
RENAL TUBERCULOSIS PRESENTING AS NEPHROCOLOCUTANEOUS FISTULA
}

Kaushal Kumar ${ }^{1}$, Smita Prasad², Ahsan Ahmed 3 , Rajesh Tiwari' ${ }^{4}$ Mahendra Singh ${ }^{5}$

\section{HOW TO CITE THIS ARTICLE:}

Kaushal Kumar, Smita Prasad, Ahsan Ahmad, Rajesh Tiwari, Mahendra Singh. "Renal Tuberculosis Presenting as Nephrocolocutaneous Fistula". Journal of Evolution of Medical and Dental Sciences 2014; Vol. 3, Issue 69, December 11; Page: 14845-14849, DOI:10.14260/jemds/2014/3994

ABSTRACT: We report a very uncommon manifestation of renal tuberculosis as nephrocolocutaneous fistula (NCCF). Patient presented with chronic discharging sinus. Radiological studies of sinus tract revealed fistulous communication of tract with colon and a completely disorganized non-functional renal unit. Colonoscopy confirmed fistulous opening in descending colon. Patient was explored retroperitoneally after starting antituberculous therapy (ATT) empirically. Nephrectomy was done but colonic fistula could not be traced due to dense adhesion in colonic area. Incision was closed after putting drain. Histopathology of excised mass was suggestive of tuberculous infection. Patient got uneventful recovery with anti tuberculous chemotherapy

KEYWORDS: Renal tuberculosis, Fistula, nephrectomy.

INTRODUCTION: Spontaneous NCCF without prior renal surgery is rarely seen in current practice. Twelve published cases of spontaneous NCCF have been reported in pubmed indexed literatures till date.[1-10] Most of the cases are found to be associated with calculus pyonephrosis. Four of them were caused by tuberculosis.[1-3] We have gone through literatures and discussed here the etiopathogenesis and management of NCCF associated with renal tuberculosis.

CASE HISTORY: A 22 year old female presented with a history of pyuria and persistent discharge of pus from an abscess on left flank which was drained elsewhere five months back. She had poor health but no history of tuberculosis, high grade fever or any other medical illness. Physical examination revealed short statured thin built body with mild pallor. Abdomen was soft with a chronic discharging sinus in left lumbar area with indurated margin. Examination of chest and vagina did not reveal any abnormalities. Urinalysis showed pyuria with growth of E. coli on urine culture. Routine blood investigations including renal function tests were normal. Fistulogram showed communication with left kidney and trickling of contrast down into descending colon. Magnetic resonance imaging urography supplemented with computerized tomography films confirmed communication of fistula tract with colon and a non-functional renal unit. Colonoscopy also revealed fistulous opening in descending colon. Patient was explored through subcostal retroperitoneal flank approach after giving three weeks of ATT empirically. Nephrectomy was done but the colonic fistula could not be dissected due to dense adhesion in colonic area. So, further dissection was deferred in anticipation of inadvertent colonic injury. Histopathology of excised tissue showed giant cell caseation granuloma suggestive of tuberculosis. Patient recovered well with six months course of antituberculous chemotherapy comprising of Isoniazid (450mg) + Rifampicin (600mg) + Ethambuto (800mg) + Pyrizinamide (1500) daily for two months followed by Isoniazid (450mg) + Rifampicin (600mg) for four months. 


\section{CASE REPORT}

DISCUSSION: NCCF is a rare but serious and formidable complication of renal tuberculosis. The kidney being a retroperitoneal organ is closely related to flank muscles on posterolateral aspect. The right renal pelvis lies in close relation with ascending colon and duodenum and the left renal pelvis with the descending colon. In cases of NCCF, the underlying pathogenesis usually involves chronic granulomatous inflammation causes peripyelitis and perinephritis with adhesion of pelvis to the adjacent colonic area.[4,5] The progressive renal parenchyma degeneration and caseous necrosis resulting in abscess formation. If left untreated, the renal abscess bursts into surrounding organs like colon and duodenum or the pus may transgress through flank muscles leading to genesis of renal fistula. ${ }^{[6]}$ Low grade fever, backache and loin pain associated with underlying renal abscess are often neglected or treated symptomatically for a long times. This is particularly seen in patient from a rural and low socioeconomic background. Such patient often present late with a non-functioning kidney and poor general condition. Diagnosis depends upon delineation of fistula track by fistulogram combined with magnetic resonance imaging.[7] Colonoscopy may be helpful in confirming the diagnosis. Serological tests and pus culture are often not helpful. Empirical ATT should be started prior to any surgical intervention. Kidney is usually not salvageable and nephrectomy along with excision of fistula tract reduces further morbidity.(8) Primary repair of colonic fistula can be done without colostomy.[9,10] Delineation of fistula tract at the time of nephrectomy is, sometimes not feasible as in our case, due to dense scarring. In this situation, extensive dissection to close fistula should be avoided as fistula opening often heals spontaneously with ATT.

We are reporting this case because of rarity of occurrence. This case report further highlights that genitourinary tuberculosis continues to thwart the advances of medical science in developing countries. A high index of suspicion and timely intervention in cases of NCCF often prevents the progression of debilitating complications.

\section{REFERENCES:}

1. Hemal AK, Gupta NP, Wadhwa SN et al. Primary repair of colonephrocutaneous fistula ingenitourinary tuberculosis: Urol. Int. 1994; 52: 41-4.

2. Yadav SP, Usha S, Poonam G, etal. Reno-colo-cutaneous fistula. a case report: Scand J Urol. Nephrol.1997; 31: 411-2.

3. Harisha RA, Nath SK, Thomas JA. Xathogranulomatous Pyelonephritis with reno colonic and cutaneous fistula: Br J Urol1987; 60: 273-4.

4. Panday JS, Desai N. Reno colo cutaneous fistula:Indian J Urol 2000;17:62-4.

5. Karljn JP, VanWessem. Cutaneous nephron colonic fistula as a consequences of a kidney stone: Southern Med Journal 2000; 93: 933-5.

6. Maed O, Nishimoto N, Oka T et al. Renocolo cutaneous fistula: Urol. Int; 41: 222-4.

7. Cohen EL, Greenstein AJ, Katz SE. Neprocolo cutaneous fistula. Use of CT scan to aid diagnosis: Comput Radiol.1983; 7: 291-4.

8. Korfopoulous AS, Murray W, Stone FJ. Nephrocutaneous fistula: J Med Soc NJ 1981; 78: 379-80.

9. Wani NA, Zargar HU, Akhar MA, et al. Cutaneousneprocolic fistula: Int Surg.1977; 62: 545-6.

10. Gibbons RP, Scimidt JD. Renocolic and renocolic cutaneous fistula: a report of three cases. J Urol1965; 94: 520-7. 


\section{CASE REPORT}

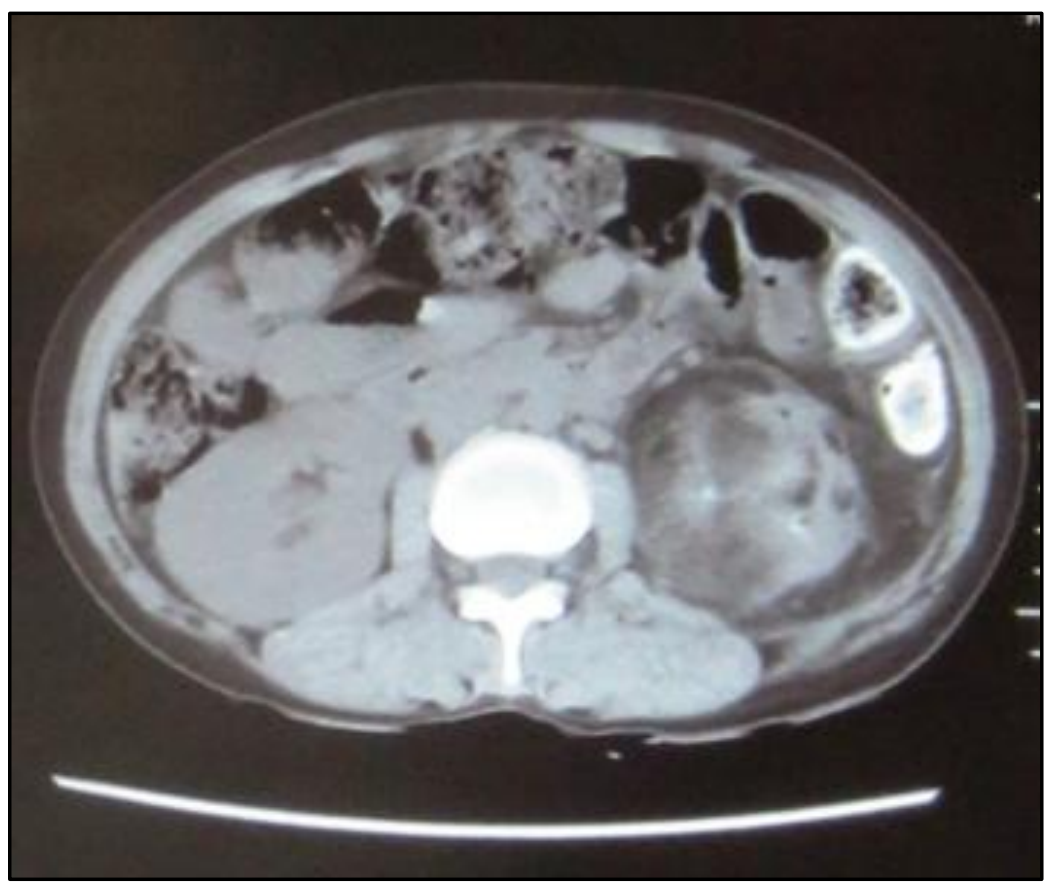

CT scan showing disorganized left kidney and trickling of contrast in descending colon

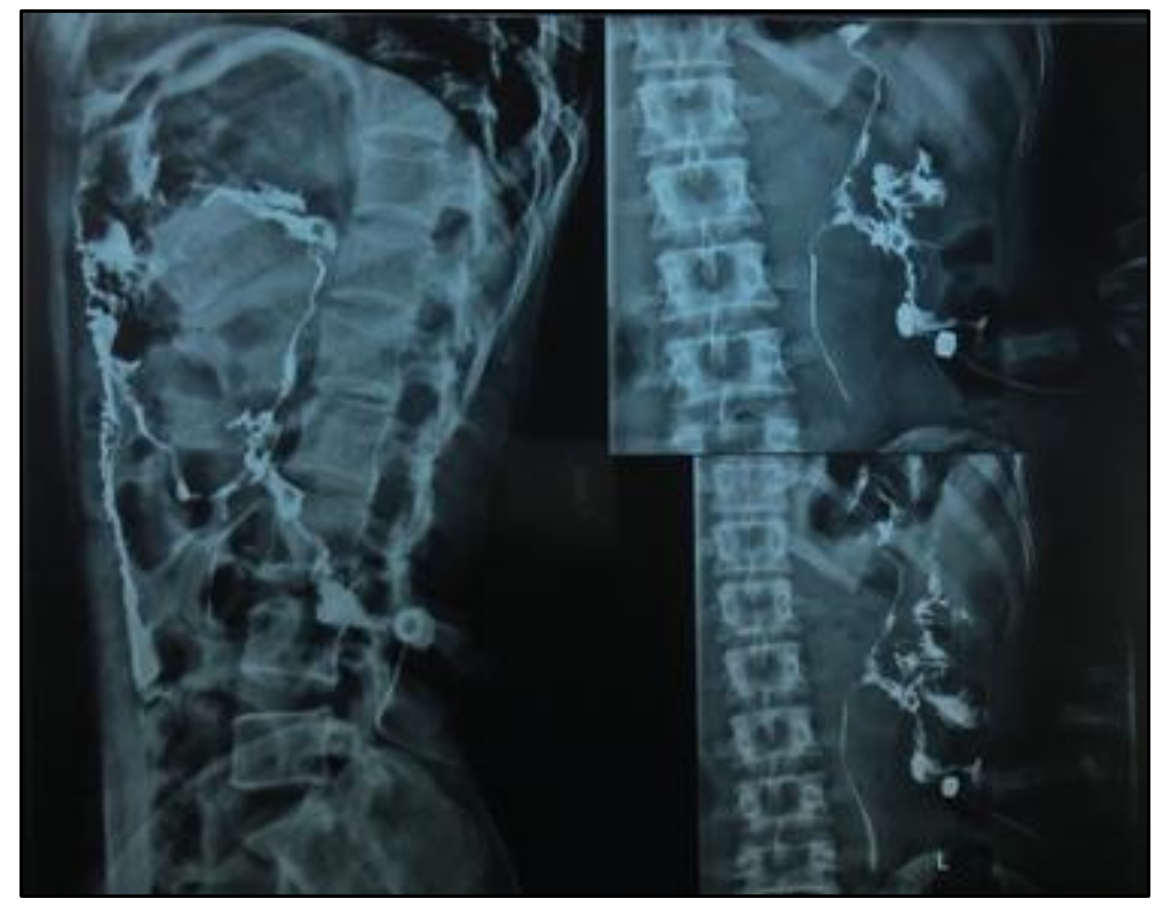

Fistulogram showing nephrocolocutaneous fistula 


\section{CASE REPORT}

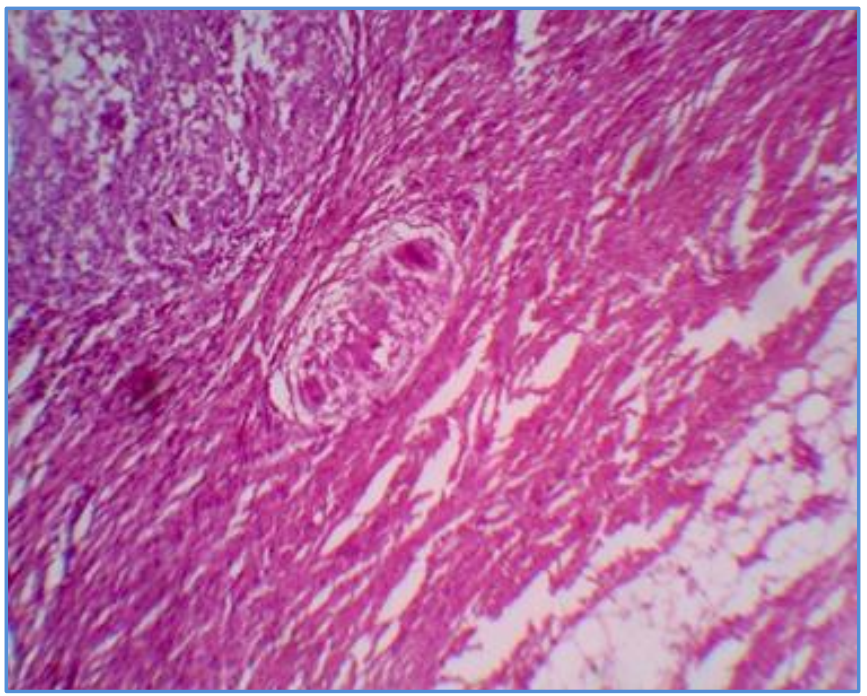

Gaint Cell caseating granuloma in renal tissue

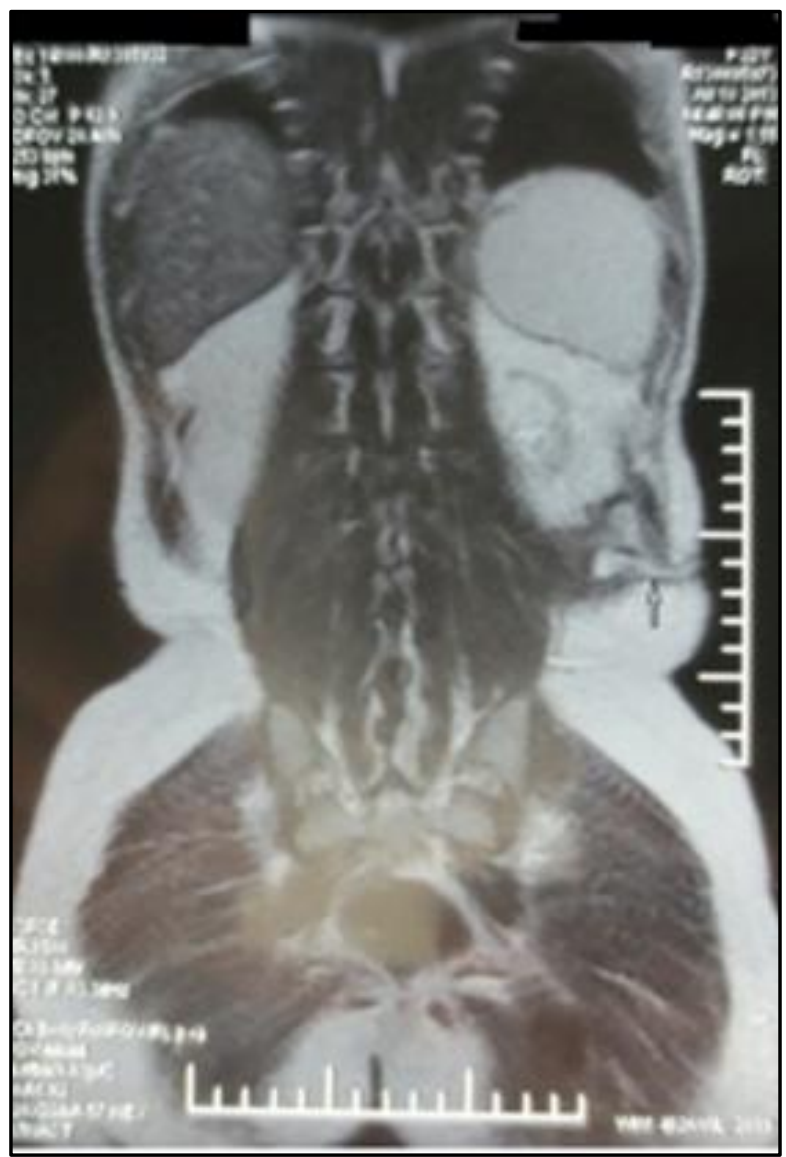

Magnetic resonance imaging of nephrocolocutaneous fistula 


\section{CASE REPORT}

\section{AUTHORS:}

1. Kaushal Kumar

2. Smita Prasad

3. Ahsan Ahmed

4. Rajesh Tiwari

5. Mahendra Singh

\section{PARTICULARS OF CONTRIBUTORS:}

1. Senior Resident, Department of Urology, Indira Gandhi Institute of Medical Sciences.

2. Senior Resident, Department of Dermatology, All India Institute of Medical Sciences.

3. Assistant Professor, Department of Urology, Indira Gandhi Institute of Medical Sciences.
4. Professor, Department of Urology, Indira Gandhi Institute of Medical Sciences.

5. Professor, Department of Urology, Indira Gandhi Institute of Medical Sciences.

\section{NAME ADDRESS EMAIL ID OF THE CORRESPONDING AUTHOR:}

Dr. Kaushal Kumar, Department of Urology, Indira Gandhi Institute of Medical Sciences, Sheikhpura, Patna-800014.

Email: surgeonkaushal@rediffmail.com

Date of Submission: 24/11/2014.

Date of Peer Review: 25/11/2014.

Date of Acceptance: 05/12/2014.

Date of Publishing: 11/12/2014. 